\title{
Representações sociais e estereótipos sobre aids e pessoas que vivem com HIV/Aids'
}

\author{
Larissa Antunes ${ }^{2}$ \\ Brigido Vizeu Camargo \\ Andréa Barbará S. Bousfield \\ Universidade Federal de Santa Catarina, Florianópolis - SC - Brasil
}

\begin{abstract}
Resumo: Este estudo teve como objetivo verificar os estereótipos presentes nas representações sociais de adolescentes sobre a aids e sobre as pessoas que vivem com HIV/Aids. Participaram 300 estudantes de escolas públicas e particulares de Florianópolis, Santa Catarina. Utilizou-se como instrumento um questionário autoaplicado, composto por questão de evocação livre, questões abertas e fechadas, e uma escala. Para análise dos dados, utilizaram-se estatística descritiva e relacional, análises lexicográficas e análise de similitude. Os resultados mostraram que as representações sociais sobre pessoas que vivem com HIV/Aids apareceram permeadas de estereótipos e elementos negativos, que remetem a aspectos emocionais e atributos físicos, e o elemento "preconceito" aparece como organizador dessa representação. Os participantes responsabilizaram as pessoas com HIV/Aids pela sua condição e rejeitaram situações em que há contato mais próximo com elas. A aids também foi citada como doença que traz sofrimento e morte e que é permeada pelo preconceito.
\end{abstract}

Palavras-chave: aids; representação social; adolescentes; estereótipos (psicologia); preconceito.

SOCIAL REPRESENTATIONS AND STEREOTYPES ABOUT AIDS AND PEOPLE LIVING WITH HIV/AIDS

\begin{abstract}
This study had the purpose of verifying the stereotypes in the social representations of the adolescents about aids and people living with HIV/Aids. The participants were 300 students from public and private schools of Florianópolis, Santa Catarina. A self-administrated questionnaire was used, and included an evocation test, objective and open ended questions and a scale. The data analysis involved descriptive and relational statistics, lexicographic analysis and similarity analysis. The results indicated that the social representation about people living with HIV/Aids is permeated of stereotypes and negative elements, which involved emotional aspects and physical attributes, and the element "prejudice" manifests as an organizer of that representation. The participants considered that people living with HIV/Aids are responsible by their condition and rejected situations of close contact with them. Further, aids was referred to as a disease that brings suffering and death, and are permeated by the prejudice.
\end{abstract}

Keywords: aids; social representation; adolescents; stereotypes (psychology); prejudice.

${ }^{1}$ Pesquisa realizada com concessão de bolsa pela Coordenação de Aperfeiçoamento de Pessoal de Nível Superior (Capes).

2 Endereço para correspondência: Larissa Antunes, Rua João Pio Duarte Silva, 94 - Florianópolis - SC - Brasil. CEP: 88037-000. E-mail: larissantunes@gmail.com. 
REPRESENTACIONES SOCIALES Y ESTEREOTIPOS SOBRE SIDA Y PERSONAS QUE VIVEN CON VIH/SIDA

\begin{abstract}
Resumen: Este estudio tuvo como objetivo verificar los estereotipos presentes en las representaciones sociales de los adolescentes sobre el sida y las personas que viven con $\mathrm{VIH} /$ Sida. Los participantes fueron 300 estudiantes de escuelas públicas y privadas de Florianópolis, Santa Catarina. Fue utilizado como instrumento un cuestionario auto administrado, compuesto por preguntas de evocación libre, preguntas abiertas y cerradas y una escala. Para análisis de los dados, fue utilizado estadística descriptiva y relacional, análisis lexicográfico y de similitude. Los resultados indicaron que la representación social de las personas que viven con $\mathrm{VIH} / \mathrm{Sida}$ aparecieron permeadas de estereotipos y elementos negativos, que remeten a aspectos emocionales $y$ atributos físicos, y el elemento "prejuicio" aparece como organizador de la representación. Los participantes responsabilizaron las personas con VIH/Sida por su condición y rechazaron situaciones de contacto más próximo con ellas. La sida fue referida como una enfermedad que trae sufrimiento y muerte, permeada por el prejuicio.
\end{abstract}

Palabras clave: sida; representación social; adolescentes; estereotipos (psicología); prejuicio.

Entre a população mundial, o número de pessoas que vivem com HIV/Aids atualmente passa de milhões. Estima-se que, no Brasil, 718 mil indivíduos vivam com HIV/ Aids, e, em média, são identificados cerca de 37 mil novos casos por ano. Nos últimos dez anos, houve aumento na taxa de detecção de aids em jovens em quase todas as regiões do Brasil, com destaque para as Regiões Norte e Nordeste, que tiveram, em 2012, um aumento de casos de $111,0 \%$ e $72,3 \%$, respectivamente, em comparação com o ano de 2003 (Ministério da Saúde, 2013).

Desde a descoberta dos primeiros casos de aids, as interpretações sobre os modos de infecção do vírus eram pautadas em termos de moralidade. A ideia prevalente de imoralidade e transgressão foi disseminada pela mídia e assimilada pela população, constituindo uma representação social sobre as pessoas que vivem com HIV/Aids (Jodelet, 2001; Labra, 2013; Seidl, Ribeiro, \& Galinkin, 2010). A partir do ano 2000, a aids começou aos poucos a ser vista como uma doença crônica e não como uma sentença de morte, o que possibilitou que as representações sociais das pessoas que vivem com essa doença refletissem uma visão mais humanizada (Labra, 2013).

As representações são um produto da interação e dos fenômenos de comunicação no interior de um grupo social, sendo fenômenos específicos que estão relacionados com um modo particular de compreender a realidade e de se comunicar com os outros (Moscovici, 2012; Vala, 2006). Uma representação é social na medida em que é partiIhada por um conjunto de indivíduos e coletivamente produzida, sendo o resultado da atividade cognitiva e simbólica de um grupo social. Ela nos guia no modo de definir e nomear os diferentes aspectos da realidade e no modo de interpretar esses aspectos, tomar decisões e nos posicionarmos perante eles (Vala, 2006).

Para Abric (2003), as representações sociais são entendidas como um sistema de interpretação da realidade, baseada em um conjunto de crenças, informações, opiniões e atitudes ante um objeto social. Estas são organizadas em torno de um duplo sistema: 
o núcleo central, que é a base comum social que define a homogeneidade do grupo, e o sistema periférico, que corresponde às bases relativas às experiências cotidianas. $O$ núcleo central desempenha um papel avaliativo e pragmático e é composto por elementos normativos e funcionais, originados do sistema de valores dos indivíduos. Já os elementos periféricos constituem os elementos mais acessíveis da representação e permitem flexibilidade e expressão individualizada das representações sociais.

A teoria das representações sociais procura compreender os fenômenos que são simultaneamente psicológicos e sociais, como as comunicações de massa, as influências sociais e os conhecimentos socialmente elaborados e compartilhados (Moscovici, 2012). Esse conhecimento socialmente elaborado e partilhado, também conhecido como senso comum, é transmitido pelas relações sociais, pela mídia e pelas comunicações interpessoais, e é construído por meio dessas trocas, já que a assimilação dessas informações orienta as práticas sociais (Jodelet, 2013).

Práticas sociais discriminatórias e preconceito com as pessoas que vivem com HIV/ Aids são consequências da concepção que perpetua as representações sobre a aids, vista como decorrência de uma transgressão das regras sociais. O preconceito refere-se a um pré-juízo ou pré-conceito elaborado sobre indivíduos e grupos, com atribuição de um valor negativo. Um dos seus efeitos é a discriminação, que se constitui em uma forma de relacionamento desigual e desfavorável dirigida ao grupo e aos seus membros (Allport, 1979). Os preconceitos sociais são estruturas psicológicas complexas, constituídas por estereótipos, que envolvem crenças a respeito de comportamentos e características pessoais ou de um grupo de pessoas (Tajfel, 1982). A função dos estereótipos é introduzir simplicidade e ordem onde existe complexidade, por meio da classificação de pessoas e grupos em categorias diversas, sendo frequentemente compartilhados socialmente. Dessa forma, a tendência dos indivíduos é selecionar uma amostra que se enquadra nos seus estereótipos e então fazê-la representativa de toda a classe (Allport, 1979).

Os conceitos de estereótipo e representação social estão interligados e remetem às imagens que a sociedade constrói dos outros, e as representações sociais estereotipadas podem sustentar práticas de discriminação social (Moliner \& Vidal, 2003). Apesar das mudanças nas representações sociais da aids, preconceitos e estereótipos relacionados às pessoas que vivem com HIVIAids ainda continuam presentes na sociedade (Labra, 2013). Essas considerações foram a base deste estudo, que buscou verificar quais os estereótipos relacionados com as representações sociais dos jovens a respeito da aids e das pessoas que vivem com HIVIAids.

\section{Método}

Este estudo é de natureza qualitativa e quantitativa, cujo delineamento é descritivo, com corte transversal. 


\section{Participantes}

Participaram deste estudo 300 estudantes do $2^{\circ}$ ano do ensino médio, de ambos os sexos, matriculados em escolas públicas e particulares de Florianópolis-SC. Eles foram selecionados de forma não probabilística, pois as turmas foram indicadas pela direção das escolas. Optou-se pelo $2^{\circ}$ ano porque, nesse período, os alunos cursam disciplinas relacionadas às áreas da saúde e educação sexual, estando, portanto, mais familiarizados com o tema.

\section{Procedimento de coleta de dados}

A pesquisa foi submetida ao Conselho do Comitê de Ética em Pesquisa com Seres Humanos e obteve parecer favorável (parecer consubstanciado $n^{\circ} 1814 / 11$ ). Após autorização do Comitê, realizou-se um contato prévio com a direção das escolas, a fim de apresentar o estudo e dar início à coleta dos dados. Não foi solicitado consentimento aos pais dos alunos, pois a autorização da direção já foi suficiente para a realização da pesquisa.

\section{Instrumentos}

Utilizou-se, na pesquisa, um questionário autoadministrado, composto de questões abertas e fechadas e aplicado em situação coletiva nas salas de aula. As questões abertas corresponderam a uma questão de evocação livre e uma questão sobre o significado da aids. As questões fechadas estavam relacionadas ao conhecimento sobre a transmissão do HIV, fontes de informação sobre aids, conhecimento de alguém que vive com HIV/Aids, distância social, caracterização dos estudantes e uma escala do tipo Likert de cinco pontos para mensuração do preconceito, com itens relacionados a pessoas que vivem com HIV/Aids.

Para elaboração da escala do tipo Likert, alguns itens foram adaptados de questões criadas por Camargo (1997) e de uma escala de atitudes criada por Moriya, Gir e Hayashida (1994), e alguns itens foram criados pelos autores do estudo. Inicialmente, a escala tinha 11 itens, com cinco afirmações favoráveis e seis desfavoráveis. Após análise dos itens por meio do índice do alfa de Cronbach, um item foi retirado da escala, obtendo-se um alfa de Cronbach de 0,70. A escala ficou composta de dez itens, com quatro afirmações favoráveis e seis desfavoráveis.

Essa escala foi apresentada com respostas dadas por um estudante fictício, indicando certo preconceito. Os participantes foram questionados quanto ao seu próprio grau de concordância com as respostas desse estudante. Após essa etapa, pediu-se aos participantes que indicassem também o grau de concordância de seus colegas e adolescentes em geral. Os participantes assinalavam suas respostas em uma escala de 1 a 7, em que 1 correspondia a nenhuma concordância e 7 a muita concordância, e 4 ao ponto médio. Após esses procedimentos, apresentou-se a mesma escala 
respondida pelo estudante fictício, para que os participantes pudessem expressar a própria opinião.

Com relação ao conhecimento científico dos estudantes sobre a transmissão do HIV, utilizou-se o subteste 1 do teste de conhecimento científico sobre o HIVIAids, referente à transmissão do vírus (Camargo, Barbará, \& Bertoldo, 2005). Era preciso ter no mínimo sete acertos para ser considerado bem informado.

Para a questão referente à distância social, foram apresentadas duas versões aos participantes, com o intuito de controlar o efeito da desejabilidade social. As perguntas foram:

- Em que situações você não se relacionaria com uma pessoa que vive com HIV/Aids?

- Em que situações você se relacionaria com uma pessoa que vive com HIVIAids?

As questões foram apresentadas de forma intercalada nos questionários, que foram distribuídos aleatoriamente para os participantes.

\section{Procedimento de análise dos dados}

Para as questões fechadas, realizaram-se análise estatística descritiva (distribuição das frequências absoluta e relativa, medidas de dispersão e tendência central) e análise estatística relacional (correlação de Pearson, teste $t$ de Student, teste qui-quadrado) por meio do Pacote Estatístico SPSS (Statistical Package Social Sciences), versão 19.0. Para a questão de evocação livre, foram utilizados os programas informáticos Evocation 2000 e Similitude 2000. O programa Evocation 2000 fornece hipóteses sobre os elementos que constituem o núcleo central da representação; o Similitude 2000 permite examinar a relação dos elementos da representação em uma estrutura gráfica (Sá, 1996).

Realizou-se análise lexical por classificação hierárquica descendente (CHD) para a questão aberta sobre a aids, com o uso do programa Alceste (Analyse Lexicale par Contexte d'un Ensemble de Segments de Texte), que ilustra relações entre as classes lexicais caracterizadas pelos segmentos de texto e seus respectivos vocabulários. Para análise descritiva desses vocabulários de cada classe, foram utilizados dois critérios: qui-quadrado significativo $\left(X^{2}>3,84, \mathrm{gl}=1\right)$ e palavras com frequência igual ou maior à frequência média, que foi sete.

\section{Resultados}

\section{Caracterização dos participantes}

Dentre os 300 participantes do estudo, 153 (51\%) eram estudantes de escolas públicas e 147 (49\%) de escolas particulares. A idade dos participantes variou entre 15 e $19 \operatorname{anos}(M=16,29 ; M o=16 ; D P=0,77)$. Com relação ao sexo, $155(51,7 \%)$ eram do sexo feminino. Quanto ao nível socioeconômico, 189 (63)\% declararam ter renda de até seis salários mínimos. Com relação a conhecer alguém que vive com aids, apenas 
113 participantes $(37,7 \%)$ declararam conhecer alguém que vive com a doença. Acerca da principal fonte de informação sobre a aids, 125 participantes $(41,7 \%)$ relataram ter a escola como principal fonte de informação sobre as formas de proteção, prevenção e transmissão do vírus.

No que diz respeito ao teste de conhecimento sobre a transmissão do HIV, os participantes em geral apresentaram uma média de 6,16 acertos (DP = 1,47), e 57,3\% dos estudantes não foram considerados bem informados, segundo os critérios do teste. Os alunos das escolas particulares apresentaram uma média de acertos $(M=6,39$; $D P=1,30)$ maior do que os alunos das escolas públicas $(M=5,94 ; D P=1,58)$, e essa diferença entre as médias foi significativa $[t(298)=2,80, p<0,01]$. Os participantes que declararam renda de sete ou mais salários mínimos apresentaram uma média de acertos $(M=6,54 ; D P=1,42)$ maior do que os participantes com renda de um a seis salários mínimos $(M=5,96$; $D P=1,46)$, sendo essa diferença nas médias significativa $[t(295)=3,28, p<0,01]$.

\section{Medidas de preconceito}

Primeiramente, pediu-se aos participantes que avaliassem a resposta dada na escala pelo estudante fictício. A pontuação dos estudantes foi abaixo do ponto médio $(M=2,70 ; D P=1,42)$, o que indicou que eles não concordaram com as respostas do sujeito apresentado no questionário. Após essa etapa, pediu-se aos participantes que comparassem a resposta dada pelo estudante fictício com as respostas que os adolescentes em geral dariam. Os participantes tiveram um escore pouco acima do ponto médio ( $M=4,25$; $D P=1,81)$, concordando que os adolescentes responderiam de forma semelhante ao estudante fictício. Posteriormente, pediu-se aos participantes que dessem suas opiniões pessoais nos itens da escala tipo Likert. A média geral dos participantes indicou uma atitude não preconceituosa em relação aos itens $(M=2,21$; $\mathrm{DP}=0,50)$. Contudo, houve uma associação positiva moderada entre a média geral de preconceito dos participantes e a média geral de concordância com as respostas do estudante fictício $(r=+0,43 ; p<0,001)$. Isso indica que quanto maior a concordância com as respostas do estudante fictício, maior é o escore dos participantes na escala. Assim, participantes que concordaram com as respostas do estudante apresentaram atitude pouco favorável com relação às pessoas que vivem com HIVIAids.

\section{Distância social}

Em situações em que a distância social é relativamente maior, os participantes afirmaram que se relacionariam com alguém que vive com HIVIAids. Observa-se que, quando as situações de relacionamento vão aumentando o grau de intimidade, os participantes vão diminuindo sua aceitação de relacionar-se com a pessoa que vive com aids. A distribuição das respostas dos 300 participantes para cada item é apresentada no Gráfico 1. 


\section{Gráfico I. Frequência das respostas dos participantes aos itens de distância social}

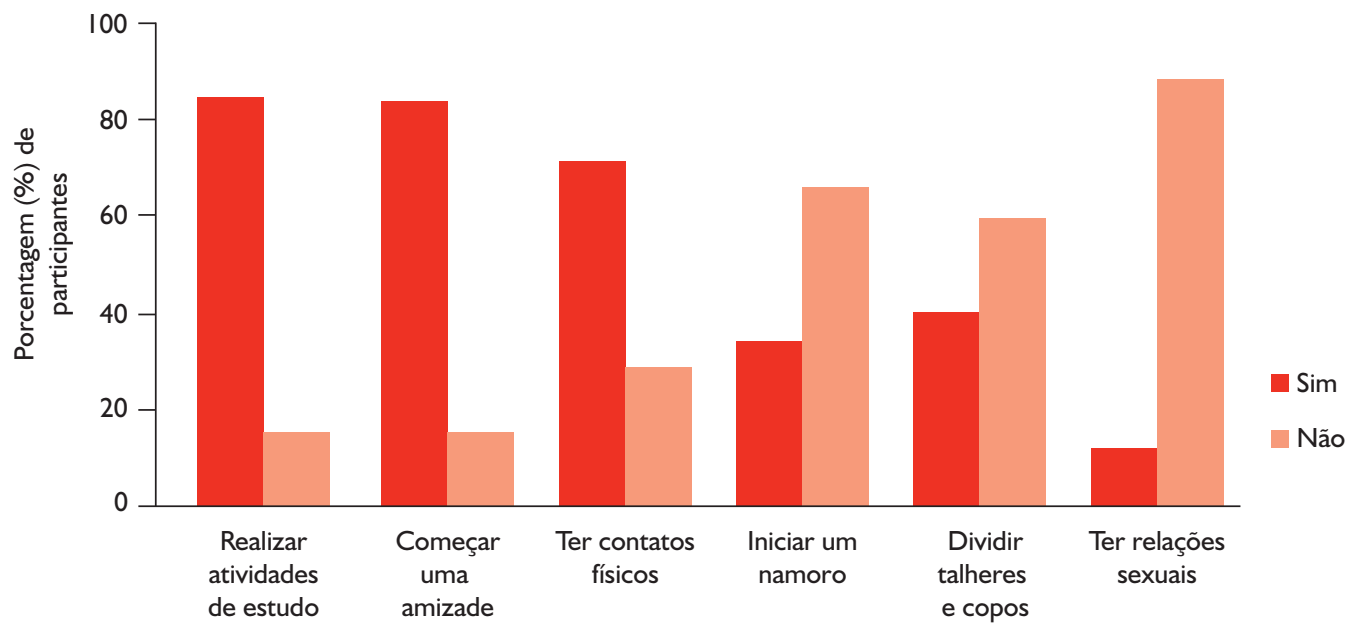

Fonte: Elaborado pelos autores.

\section{Representações sociais das pessoas que vivem com HIV/Aids}

A partir da questão de evocação livre com a frase indutora "pessoa que vive com HIVIAids", obtiveram-se 1.500 evocações com 273 palavras diferentes. A frequência média das evocações foi de 19,10, e a ordem média de evocação (OME) foi de 3 . Com base nesses valores, foi gerado um diagrama com quatro quadrantes, conforme Tabela 1.

Tabela I. Diagrama das evocações a partir da frase indutora "pessoa que vive com HIV/Aids" $(n=300)$

\begin{tabular}{|c|c|c|c|c|c|c|}
\hline & \multicolumn{3}{|c|}{ OME $>3,0$} & \multicolumn{3}{|c|}{ OME $<3,0$} \\
\hline & Elemento & $f$ & OME & Elemento & $f$ & OME \\
\hline \multirow[t]{12}{*}{$f>=19$} & Preconceito* & 114 & 2,72 & Morte & 55 & 3,29 \\
\hline & Tristeza & 67 & 2,91 & Cuidados & 35 & 2,02 \\
\hline & Sofrimento* & 54 & 2,55 & Medicamentos & 26 & 3,11 \\
\hline & Doença & 52 & 2,26 & Vírus & 21 & 3,19 \\
\hline & Sexo & 52 & 2,59 & & & \\
\hline & Preservativo* & 50 & 2,96 & & & \\
\hline & Medo & 34 & 2,67 & & & \\
\hline & Doente* & 31 & 1,93 & & & \\
\hline & Tratamento* & 26 & 2,53 & & & \\
\hline & Discriminação* & 25 & 2,52 & & & \\
\hline & Irresponsabilidade* & 22 & 2,90 & & & \\
\hline & Descuido* & 21 & 2,90 & & & \\
\hline
\end{tabular}


Tabela I. Diagrama das evocações a partir da frase indutora "pessoa que vive com HIV/Aids" ( $\mathbf{n}=\mathbf{3 0 0 )}$ (conclusão)

\begin{tabular}{|c|c|c|c|c|c|c|}
\hline & \multicolumn{3}{|c|}{ OME $>3,0$} & \multicolumn{3}{|c|}{ OME $<3,0$} \\
\hline & Elemento & $f$ & OME & Elemento & $f$ & OME \\
\hline \multirow[t]{12}{*}{$f<=19$} & Dificuldades & 16 & 2,43 & Vida normal & 18 & 3,16 \\
\hline & Pessoa normal & 16 & 2,87 & Prevenção & 17 & 3,23 \\
\hline & Problemas & 14 & 2,78 & Irresponsável & 17 & 3,64 \\
\hline & Superação & 14 & 2,64 & Proteção & 15 & 3,46 \\
\hline & Esperança & 14 & 2,71 & Dor & 15 & 3,06 \\
\hline & Pena & 14 & 2,57 & Angústia & 14 & 3,42 \\
\hline & Vergonha & 14 & 2,35 & Saúde & 13 & 3,92 \\
\hline & Infelicidade & 13 & 2,69 & Sangue & 11 & 3,09 \\
\hline & Preocupação & 12 & 2,87 & Solidão & 10 & 3,80 \\
\hline & Exclusão & 11 & 2,72 & Rejeição & 10 & 3,60 \\
\hline & Arrependimento & 9 & 2,77 & Falta de informação & 10 & 3,80 \\
\hline & & & & Sem cura & 9 & 3,44 \\
\hline
\end{tabular}

* Elementos confirmados como pertencentes ao núcleo central, por meio da proporção entre o número total de evocações e o número de evocações das palavras mais importantes (SÁ, 1996).

Fonte: Elaborada pelos autores.

A partir da análise estrutural das evocações livres, observou-se, no primeiro quadrante (Tabela 1), a presença dos elementos que possivelmente organizam a representação social dos participantes a respeito das pessoas que vivem com HIV/Aids, por serem os mais frequentes e evocados primeiramente pelos sujeitos (Sá, 1996). Neste estudo, os elementos constituintes do núcleo central indicam que a representação social das pessoas que vivem com HIV/Aids para os participantes está relacionada a aspectos biológicos da doença, como "tratamento", "doença" e "doente", a aspectos relacionados à transmissão da doença, como "irresponsabilidade" e "descuido", e a elementos negativos, como "sofrimento" e "tristeza".

Com relação aos elementos periféricos, percebe-se o predomínio dos elementos ligados ao sofrimento psicológico, como "infelicidade", "vergonha", "exclusão" e "arrependimento", e dos elementos ligados às consequências da doença, como "cuidados" e "medicamentos". Em decorrência da análise de similitude, verificou-se que o elemento "preconceito" aparece como central e está conectado aos elementos que aparecem em negrito na Figura 1.

Conforme exposto na Figura 1, a forte conexão do elemento central e organizador "preconceito" com as categorias em negrito indica que a representação social desse grupo com relação às pessoas que vivem com HIV/Aids se organiza a partir desses elementos. Ou seja, a aids é vista como uma doença que é adquirida por se adotar um comportamento irresponsável, como o não uso do preservativo, que tem como consequência a contaminação pelo vírus HIV. 
Figura I. Árvore dos elementos associados às pessoas que vivem com HIV/Aids Filtro $5(n=300)$

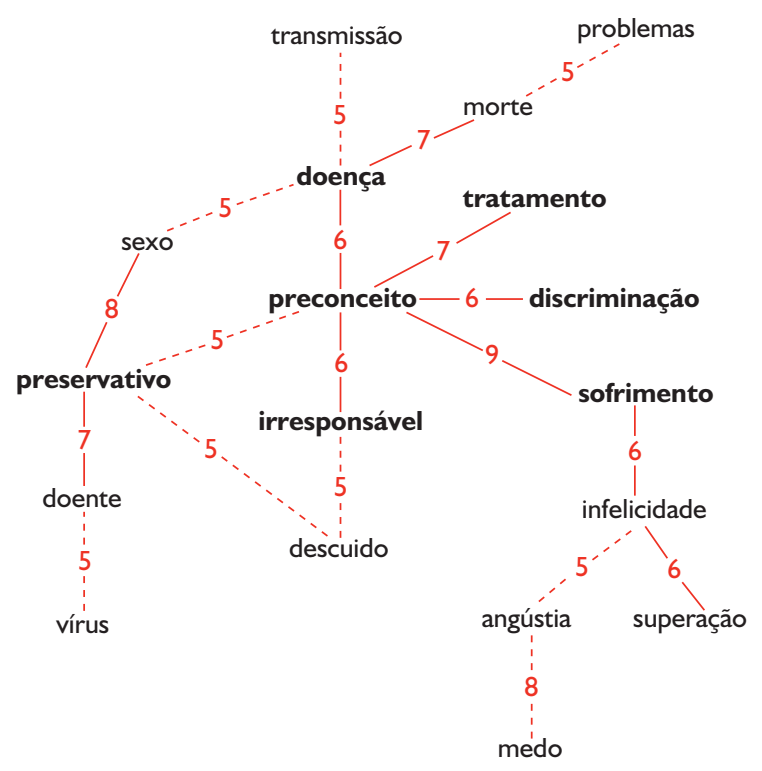

Fonte: Elaborada pelos autores.

\section{Representação social da aids}

Solicitou-se que os participantes respondessem à seguinte pergunta: "O que você pensa a respeito da aids?". Com relação a essa questão, a CHD referente ao corpus "aids" evidenciou cinco classes lexicais. Das 300 Unidades de Contexto Elementar (UCE) selecionadas, 276 foram consideradas pela CHD, correspondendo a $92 \%$ do total. A frequência média das palavras analisadas foi igual a 15,54. A classe 4 apresentou o maior número de UCEs, com 88 (31,38\%), sendo a que caracteriza, em maior proporção, esse corpus, conforme exposto na Figura 2.

Segundo a Figura 2, a primeira partição do corpus inicial gerou dois subcorpus: de um lado, as classes 2, 3 e 5; e do outro, as classes 1 e 4 . A segunda partição distinguiu a classe 1 da 4 . A terceira partição separou a classe 5 das classes 2 e 3 . E a quarta e última partição discerniu as classes 2 e 3.

Os conteúdos da classe 4 estão associados aos escores baixos obtidos na escala de preconceito $\left(X^{2}=8,99\right)$ e às pessoas que não conhecem alguém que vive com HIV/Aids $\left(X^{2}=4,73\right)$. Os elementos dessa classe estão relacionados com a prevenção do HIV, como pode ser ilustrado neste extrato: "Acredito que em certas ocasiões é causada por falta de responsabilidade, tanto de quem passa ou quem recebe, pois com tantos avisos e formas de prevenção que nos é oferecido, pode ser chamado como uma doença de irresponsável" (rapaz, 16 anos, escola particular). Observa-se por esse trecho que essa classe está relacionada com aspectos ligados ao fato de não se prevenir, considerado como uma irresponsabilidade. 


\section{Figura 2. Dendograma da classificação hierárquica descendente do corpus "aids"}

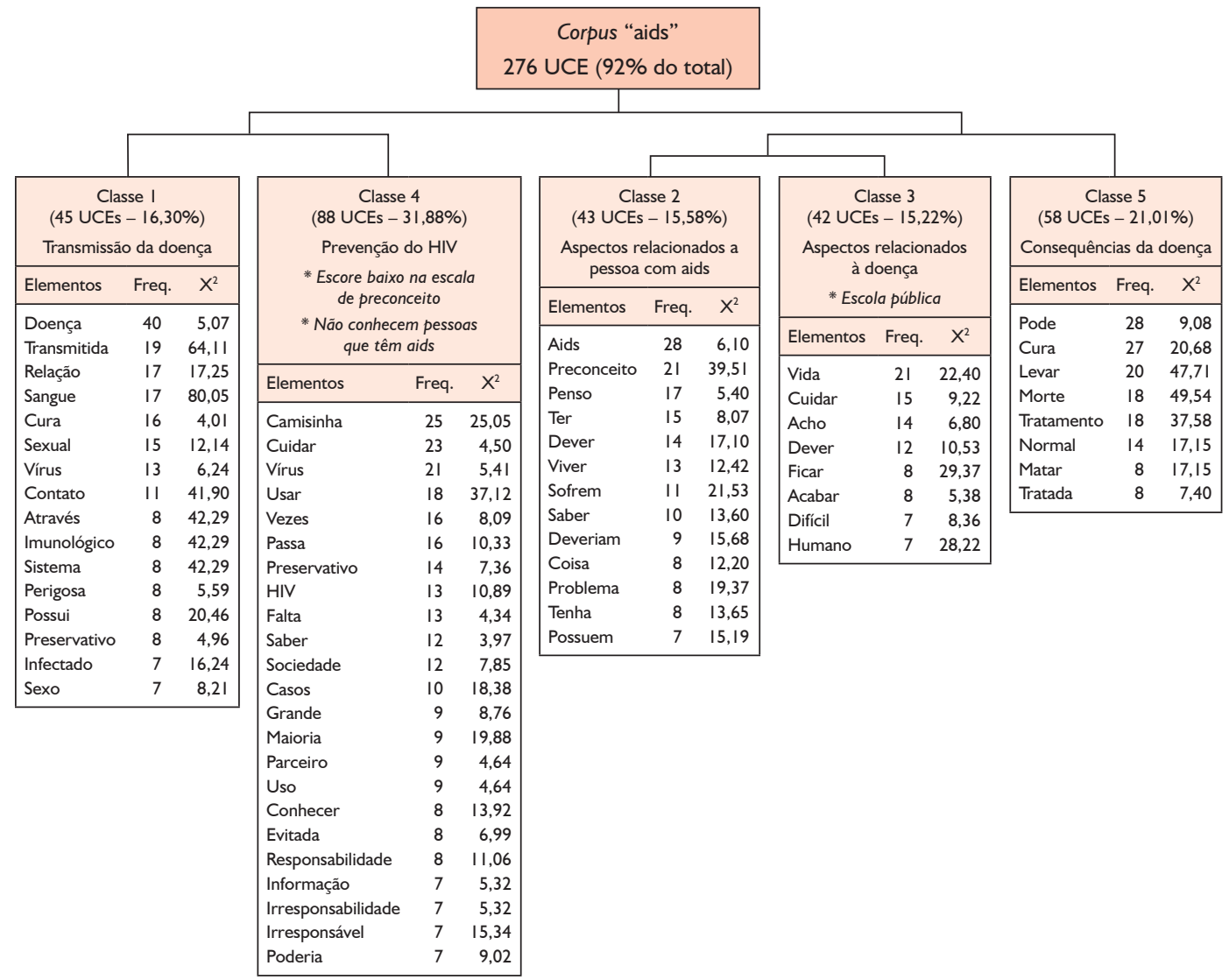

Fonte: Elaborada pelos autores.

A classe 1 está relacionada à transmissão e às formas de transmissão da doença. $O$ trecho a seguir ilustra bem essa classe: "É uma doença que pode ser transmitida por pessoas para outras pessoas, através de relações sexuais sem proteção ou por contato com sangue infectado" (rapaz, 16 anos, escola pública). A doença também foi representada como perigosa, algo que é temido e que gera medo do contágio: "É um vírus muito perigoso, de fácil contágio e que pode causar a morte do infectado, possui prevenção, mas não tem cura" (rapaz, 16 anos, escola particular).

A classe 5 está relacionada com as consequências da doença, por meio dos elementos "cura", "morte", "tratamento" e "matar", o que pode ser exemplificado por este trecho: "É uma doença difícil de curar, mas tem sim vários tratamentos, mas se não for tratada, pode levar a pessoa à morte" (moça, 17 anos, escola pública). Entretanto, os elementos "normal" e "pode", presentes nessa classe, indicam que os participantes consideram que a pessoa que vive com HIVIAids pode levar uma vida normal, com a realização do tratamento adequado. 
A classe 2 está associada aos elementos relacionados a pessoas que vivem com HIV/ Aids, como o "preconceito": "não sei exatamente sobre a doença, mas existe muito preconceito com quem tem o vírus, e por esse preconceito a pessoa deve se sentir excluída, incapaz, sem vontade de viver, deixa de fazer muitas coisas por esse problema, por esse preconceito" (moça, 15 anos, escola pública).

Percebe-se, por meio dessa fala, que as pessoas que vivem com HIVIAids são vistas como pessoas infelizes e que sofrem preconceito. Observa-se então que a representação a respeito da pessoa que vive com HIVIAids, nessa classe, traz elementos relacionados a aspectos negativos.

Por fim, a classe 3 está associada significativamente com alunos da escola pública $\left(X^{2}=5,99\right)$ e traz aspectos relacionados à doença. $A$ aids é representada nessa classe como uma doença que exige cuidados, como observado neste fragmento: "Acho que a pessoa que tem aids deve seguir sua vida sem preocupações e ter cuidado com você e com outras pessoas ao seu lado" (moça, 17 anos, escola pública). O elemento "cuidado" também está associado com a proteção, como ilustrado neste trecho: "Eu acho que é uma doença séria e que devemos tomar o máximo de cuidado para não contaminar ou ser contaminado, e devemos escolher bem nossos parceiros e nos proteger" (rapaz, 16 anos, escola particular). A aids é representada nessa classe como uma doença que traz o perigo do contágio se não houver cuidado e proteção.

\section{Discussão e conclusão}

Os participantes deste estudo demonstraram pouco conhecimento sobre a transmissão do HIV. A falta de informação sobre a aids pode gerar concepções errôneas das formas de transmissão do vírus. É importante destacar que adolescentes que demonstram maior conhecimento sobre as formas de prevenção e transmissão identificam com maior precisão comportamentos que facilitariam a contaminação, o que indica que o comportamento dos adolescentes está associado à qualidade das informações que possuem. Ademais, o medo do contágio, proveniente da falta de informação sobre a transmissão do HIV, também pode gerar concepções errôneas sobre a doença, acirrando o preconceito e as atitudes discriminatórias com pessoas que vivem com HIV/ Aids (Collani, Grumm, \& Streicher, 2010; Seidl et al., 2010).

O conteúdo dos estereótipos relacionados a pessoas que vivem com HIVIAids incorpora vários tipos de características, fazendo referência a aparência física, papéis sociais e atributos negativos ou positivos. Isso permite a ocorrência da generalização de atributos para todas as pessoas pertencentes a esse grupo, formando-se os estereótipos (Tajfel, 1982). As características físicas atribuídas às pessoas que vivem com HIV/Aids envolvem elementos como "doente", "magreza", fraqueza", "contagioso", "infectado" e características do comportamento, como "irresponsável". O elemento "infectado" foi utilizado ora para fazer referência à doença, ora à pessoa com HIV/Aids. Quando relacionado à pessoa que vive com HIVIAids, esse elemento remete à ideia de contágio, situação em que a proximidade oferece perigo. 
A crença de que o contato casual com as pessoas com HIVIAids é um meio de contágio e transmissão do HIV decorre das representações que a sociedade compartilha a respeito da aids, relacionadas a outras doenças contagiosas. A aids foi concebida como uma doença que poderia ser transmitida também por meio de saliva, suor e contato físico, como o toque e o abraço. Por meio das crenças, o indivíduo organiza uma visão coerente do objeto, elaborando representações sobre o fenômeno. Essas representações se constituem em um saber prático, que guia as ações e os comportamentos dos indivíduos. Assim, as pessoas convivem com o que se armazenou de conhecimentos sobre a aids e sobre o que foi sendo construído socialmente sobre essa epidemia, justificando suas práticas discriminatórias com a pessoa que vive com HIVIAids em função da ameaça de contaminação (Jodelet, 2001).

As representações sociais dos participantes evidenciaram alguns elementos normativos relacionados às pessoas que vivem com HIVIAids e que aparecem como pertencentes ao núcleo central da representação. Esses elementos associam-se com a responsabilização da pessoa com HIV/Aids pela sua condição. O elemento "doente" se constitui em um estereótipo relacionado às pessoas que vivem com HIVIAids e remete a perda de peso, magreza, fraqueza e cansaço, atributos físicos que ganharam destaque em um primeiro momento da epidemia (Galvão, 2009). Além disso, a pessoa que vive com HIVIAids é vista como alguém condenado ao sofrimento e à morte, ao isolamento e à tristeza, já que a aids é vista como uma sentença de morte tanto física quanto social (Galvão, 2009).

Os participantes demonstraram uma oposição ao contato íntimo com os membros do exogrupo, com rejeição da maioria das situações em que havia maior contato e intimidade com as pessoas que vivem com HIVIAids. Atos discriminatórios para com as pessoas que vivem com HIVIAids estão relacionados com comportamentos de distância social, com a atribuição de responsabilidade e de estereótipos, constituindo-se em obstáculos para a convivência social (Collani et al., 2010; Seidl et al., 2010).

Apesar de os participantes relatarem distanciamento de situações em que há contato mais próximo com a pessoa que vive com HIVIAids, os estudantes em geral não demonstraram preconceito ao responderem à escala com itens relacionados às pessoas que vivem com HIV/Aids. Já na análise das respostas do estudante fictício em comparação com as que os adolescentes em geral dariam, os participantes afirmaram haver uma semelhança das respostas. Nesse item, os estudantes estão respondendo sobre outros adolescentes, o que lhes permite tomar certa distância do objeto e reduzir o nível de implicação (Abric, 2005). Isso possibilita que os participantes possam expressar suas próprias ideias sob a proteção do outro, expressando opiniões mais negativas a respeito das pessoas que vivem com HIVIAids sem se preocupar com julgamentos (Camargo et al., 2009). Dessa forma, quando os participantes compararam suas próprias respostas com as do sujeito fictício do questionário, tenderam a discordar mais do que quando compararam as respostas do sujeito com as supostas opiniões dos adolescentes em geral. 
Com relação à fonte de informação sobre a aids, os participantes destacaram a escola como principal fonte de informação a respeito das formas de transmissão e prevenção do HIV. A abordagem atual de divulgação de conhecimentos sobre a aids menciona os conteúdos de forma isolada e não aprofundada. É preciso que os jovens não sejam apenas recebedores passivos dessas informações, mas que possam utilizá-las em sociedade e em seu cotidiano. Dessa forma, é importante que o jovem receba a mensagem e possa se posicionar perante ela, para que possa ocorrer a aquisição de conhecimento e atitudes favoráveis a práticas preventivas (Bousfield \& Camargo, 2011).

O objetivo deste estudo foi verificar quais são os estereótipos relacionados com as representações sociais dos jovens a respeito da aids e das pessoas que vivem com HIV/ Aids. As representações sociais dos participantes a respeito da aids envolvem elementos negativos; a doença é vista como algo fatal e que traz sofrimento e dificuldades para as pessoas que vivem com HIVIAids. Esse discurso estereotipado sobre a aids está presente desde o início da epidemia, bem como a culpabilização da pessoa que vive com HIVIAids (Jodelet, 2001). A atribuição de responsabilidade e culpabilização dessas pessoas pode ser verificada neste estudo, sendo um elemento presente nas representações sociais dos adolescentes respondentes. Os estereótipos presentes nas representações sociais dos participantes remetem também a atributos físicos relacionados à aids. Essas representações sociais estereotipadas podem reforçar o preconceito e as práticas discriminatórias, como o distanciamento das pessoas que vivem com HIVIAids.

Esta pesquisa pode contribuir para os estudos sobre preconceito com as pessoas que vivem com HIV/Aids, principalmente no grupo estudado nesta pesquisa. Os dados mostram que, apesar das campanhas contra o preconceito, os participantes demonstram ter atitudes discriminatórias com relação a situações de contato mais próximo com pessoas que vivem com HIVIAids. Dessa forma, grupos focais, campanhas e programas educativos direcionados ao contexto vivenciado pelos jovens poderiam contribuir para a prevenção da doença e para atenuar o preconceito e a discriminação, já que é na escola que ocorrem as principais interações sociais com diversos colegas. A discriminação de pessoas que vivem com HIVIAids é um assunto estudado por várias áreas no campo da saúde, e, pela sua frequente ocorrência em nossa sociedade, esse tema tem diferentes aspectos que podem ser abordados em pesquisas futuras.

\section{Referências}

Abric, J. C. (2003). Abordagem estrutural das representações sociais: desenvolvimentos recentes. In P. H. F. Campos \& M. C. S. Loureiro (Orgs.). Representações sociais e práticas educativas (pp. 37-57). Goiânia: Editora da UCG.

Abric, J. C. (2005). A zona muda das representações sociais. In D. C. O. Oliveira \& P. H. F. Campos. Representações sociais: uma teoria sem fronteiras (pp. 23-34). Rio de Janeiro: Museu da República. 
Allport, G. W. (1979). The nature of prejudice. New York: Basic Books.

Bousfield, A. B. S., \& Camargo, B. V. (2011). Divulgação do conhecimento científico sobre Aids e representações sociais. Acta Colombiana de Psicología, 14(1), 31-45. Recuperado em abril, 2014, de http://www.scielo.org.co/scielo.php?script=sci_ arttext\&pid=S0123-91552011000100004.

Camargo, B. V. (1997). Communication et prévention du Sida. Tese de doutorado, École des Hautes Études em Sciences Sociales, Paris, França.

Camargo, B. V., Barbará, A., \& Bertoldo, R. B. (2005). Um instrumento de medida da dimensão informática da representação social da Aids. In IV Jornada Internacional e II Conferência Brasileira sobre Representações Sociais. Textos Completos da IV Jornada Internacional e II Conferência Brasileira sobre Representações Sociais, João Pessoa, PB, Brasil, 1385-1395.

Camargo, B. V., Bertoldo, R. B., \& Barbará, A. (2009). Representações sociais da Aids e alteridade. Estudos e Pesquisas em Psicologia, 9(3), 710-723.

Collani, G. V., Grumm, M., \& Streicher, K. (2010). An investigation of the determinants of stigmatization and prejudice toward people living with HIV/Aids. Journal of Applied Social Psychology, 40(7), 1747-1766. DOI: 10.1111/j.1559-1816. 2010.00638.x.

Galvão, A. C. (2009). Os muros (in)visíveis do preconceito: um estudo das representações sociais das pessoas que vivem com HIVIAids. Dissertação de mestrado, Universidade de Brasília, Brasília, DF, Brasil.

Jodelet, D. (2001). Representações sociais: um domínio em expansão. In D. Jodelet (Org.). As representações sociais (pp. 187-203). Rio de Janeiro: Eduerj.

Jodelet, D. (2013). Culture and health practices. In A. S. de Rosa (Org.). Social representations in the social arena (pp. 153-165). New York: Routledge.

Labra, O. (2013). Social representations of HIVIAids in mass media: some important lessons for caregivers. International Social Work, O(0), 1-11. DOI: 10.1177/0020 872813497380 .

Ministério da Saúde (2013, dezembro). Programa Nacional de DST e Aids. Boletim Epidemiológico - Aids e DST. 2(1-16). Brasília.

Moliner, P., \& Vidal, J. (2003). Stéréotype de la catégorie et noyau de la représentation sociale. Revue Internationale de Psychologie Sociale, 1, 157-175.

Moriya, T. M., Gir, E., \& Hayashida, M. (1994). Escala de atitude frente à Aids: uma análise psicométrica. Revista Latino-Americana de Enfermagem, 2(2), 37-53. Recuperado em abril, 2014, de http://dx.doi.org/10.1590/S0104-11691994000200004.

Moscovici, S. (2012). A psicanálise, sua imagem e seu público. Petrópolis: Vozes. (Obra original publicada em 1961). 
Sá, C. P. (1996). Núcleo central das representações sociais. Petrópolis: Vozes.

Seidl, E. M. F., Ribeiro, T. R. A., \& Galinkin, A. L. (2010). Opiniões sobre pessoas com HIV/Aids. Psico-USF, 15(1), 103-112.

Tajfel, H. (1982). Grupos humanos e categorias sociais (Vol. 1). Lisboa: Horizonte.

Vala, J. (2006). Representações sociais e psicologia social do conhecimento quotidiano. In J. Vala \& M. B. Monteiro (Orgs.). Psicologia social (7a ed., pp. 457-502). Lisboa: Calouste Gulbenkian.

Submissão: 23.7.2014

Aceitação: 21.8 .2014 